\title{
Intention to Quit among Smokers in Kazakhstan: Data from 2014 Global Adult Tobacco Survey
}

\author{
Qian Wang ${ }^{1, *}$, Komi Mati $^{2}$ \\ ${ }^{1}$ Department of Public Health, Shanghai Jiao Tong University School of Medicine, Shanghai, China \\ ${ }^{2}$ Dobson DaVanzo \& Associates, Vienna, VA 22180, USA
}

\section{ARTICLE INFO}

\section{Article History}

Received 17 March 2018

Accepted 16 January 2019

Keywords

Global Adult Tobacco Survey intention to quit

Kazakhstan

\begin{abstract}
Kazakhstan is one of the countries with higher-than-average smoking prevalence and tobacco-related mortality. Intention to quit is a key step toward smoking cessation, yet has not been studied in Kazakhstan. This study explored prevalence and correlates of intention to quit among smokers in Kazakhstan. We drew data from the nationally representative survey, the Global Adult Tobacco Survey (GATS), conducted during 2014 in Kazakhstan. Our sample consisted of 649 smokers aged $\geq 15$ years. We examined prevalence of intention to quit by demographics, knowledge of tobacco-related diseases, nicotine dependence, attempt to quit in the past 12 months, household smoking restrictions, and awareness of antismoking messages. Univariate and multivariate logistic regressions were used to test the significance of these correlates. Prevalence of intention to quit was around $75.9 \%$ among smokers. Older age $(p<0.001)$, knowledge of tobacco-related diseases $(p<0.01)$, moderate nicotine dependence $(p<0.001)$, attempt to quit within the past 12 months $(p<0.001)$, and having household smoking restrictions $(p<0.001)$ were all significant correlates. We suggest investing in efforts to promote cessation activities for smokers of all ages, to disseminate comprehensive information on tobacco-related diseases, and to uphold and strengthen policies on smoking bans.
\end{abstract}

(c) 2019 Atlantis Press International B.V.

This is an open access article distributed under the CC BY-NC 4.0 license (http://creativecommons.org/licenses/by-nc/4.0/).

\section{INTRODUCTION}

Globally, the World Health Organization (WHO) estimated that the total prevalence of smoking among those aged $\geq 15$ years decreased from $26.9 \%$ in 2000 to $22.1 \%$ in 2010 [1]. Among all WHO regions, Europe had the highest total prevalence of smoking, with $37.3 \%$ in 2000 and $32.0 \%$ in 2010 [1]. As a country in the WHO European Region, Kazakhstan has seen its total prevalence of smoking among those aged $\geq 18$ years steadily increase from $23 \%$ in 2003 to $27 \%$ in 2007 [2], and decrease only slightly to $26.5 \%$ in 2012 [3]. Furthermore, its annual consumption of tobacco per capita was ranked 24th globally, and 16th in the WHO European Region [4].

Smoking is one of the most extensively studied health risk behaviors, with $>60,000$ studies published on the hazards of smoking [5]. It has been associated with the premature deaths [6], at least 12 cancers [7], type 2 diabetes [8], and chronic obstructive pulmonary disease [9]. To tackle tobacco use, Kazakhstan adopted the law "On ratification of the World Health Organization Framework Convention for the Tobacco Control" in 2006 [10], and continued to adopt a code on the health of the people and the health care system in 2009, which included a detailed statement on tobacco control (Article 159) [11]. In spite of these efforts, the projected tobacco-related premature deaths in Kazakhstan increased to $>50 \%$ of all smokers in 2014 [12].

Most smokers begin smoking during their adolescence, and continue to be regular users during adulthood. Quitting smoking reduces the

"Corresponding author. Email: michellewang1@hotmail.com toll of tobacco-related diseases and increases life expectancy among smokers, regardless of the age at which cessation occurs $[13,14]$. Nonetheless, the greatest benefits of quitting smoking are often seen among those with a shorter smoking history [13]. In addition, quitting smoking before the age of 30 years could reduce most tobacco-related mortality $[15,16]$. Intention to change a behavior is the most proximate predictor of the behavior [17]. Intending to quit smoking is often the first step toward quitting smoking completely $[18,19]$, as it is linked to past quitting attempts, Heaviness of Smoking Index (HSI), exposure to second-hand smoking, awareness of health consequences of smoking, household smoking restrictions, and exposure to antitobacco messages [20-23]. However, to our knowledge, no study has examined intention to quit and its correlates among smokers in Kazakhstan. Therefore, the purpose of our study was to fill this gap in the literature. Given the relatively high prevalence of tobacco use and projected tobacco-related premature deaths in Kazakhstan, examining intention to quit and identifying factors associated with it may contribute to evidence-based strategies to encourage quitting at individual as well as population level [24].

\section{METHODS}

\subsection{Data}

We used nationally representative data from the Global Adult Tobacco Survey (GATS) conducted during 2014 in Kazakhstan. As a component of the Global Tobacco Surveillance System, GATS 
is a global standard for systematically monitoring adult tobacco use and tracking key tobacco control indicators [25]. The 2014 GATSKazakhstan was conducted as a household survey of persons aged $\geq 15$ years by the Information Computing Center of the Committee on Statistics of the Republic of Kazakhstan in collaboration with the National Center for Problems of Healthy Lifestyle Development, and the Ministry of Health and Social Development of the Republic of Kazakhstan [26]. A multistage, geographically clustered sample design was used to produce nationally representative data. Detailed information about the sampling framework and the study design has been published [26].

\subsection{Measures}

Intention to quit was the outcome variable of interest and measured by the question "Which of the following best describes your thinking about quitting smoking?” Response options included intending to quit within "next month", "next 12 months", and "will quit but not within the next 12 months", and "not interested in quitting". Responses were dichotomized, with those answering "next month", "next 12 months", and "will quit but not within the next 12 months" as having quit intentions, and those answering "not interested in quitting" as not having quit intentions. This variable was dichotomized for two reasons. First, we were interested in whether people had the intention to quit, not in the strength of this intention. Second, the frequency distribution of this variable was highly skewed with very few people in the intending to quit within "next month" and "next 12 months" categories.

Knowledge of tobacco-related disease was an independent variable. It was measured by a set of 12 questions, each of which asked respondents if they knew or believed smoking would cause a particular disease. Smokers who answered "yes" to more than six of the questions were considered as having knowledge of tobacco-related diseases, while those who answered "yes" to six or less questions were considered as not having enough knowledge of tobaccorelated diseases.

Nicotine dependence was an independent variable and measured using HSI. HSI was calculated as the sum of two categorical variables: number of cigarettes smoked per day (0: 0-10, 1: 11-20, 2: 21-30, 3: >31) and time to first cigarette after waking (0: $>61 \mathrm{~min}$, 1: 31-60 $\mathrm{min}, 2: 6-30 \mathrm{~min}, 3: \leq 5 \mathrm{~min})$. HSI has been shown to be a reliable and valid measure of nicotine dependence, and was found similar to the Fagerstrom Tolerance Questionnaire and the Fagerstrom Test for Nicotine Dependence in identifying nicotine dependence $[27,28]$.

Attempt to quit was analyzed as an independent variable measured by the question "During the past 12 months, have you tried to stop smoking?" Those who answered "yes" were considered having attempted to quit, and those answering "no" were considered as not having attempted to quit. We only considered quit attempts that lasted for $>1$ day as valid, and in our sample, $<10$ people had a quit attempt that lasted for $<1$ day.

Household smoking restrictions was an independent variable measured by the question "Which of the following best describes the rules about smoking inside of your home?" Those who answered "smoking is allowed inside of your home", "there are no rules about smoking in your home", and "smoking is generally not allowed inside of your home but there are exceptions" were considered as having no restrictions, and those who answered "smoking is never allowed inside of your home" was considered as having household restrictions.

Awareness of antismoking messages was an independent variable measured by a set of five questions; each of which asked if the respondents noticed antismoking information in a particular media outlet during the past 30 days. Smokers who answered "yes" to at least one of the five questions were considered as having awareness of antismoking messages, and those who answered "no" or "don't know" to all five questions were considered as not having awareness of antismoking messages.

Demographic covariates included the following. (1) Age: 15-29 years (young); 30-54 years (middle-aged); and $\geq 55$ years (old). (2) Gender: male vs. female. (3) Education: low education (no formal schooling, primary education, incomplete basic education); secondary education (secondary general education, secondary technical/vocational education); and higher education (some college/university, college/university completed, postgraduate degree completed). (4) Employment status: employed (government/nongovernment employee, self-employed) vs. unemployed (student, homemaker, retired, unemployed). (5) Income: low income (income only enough for food, income does not even allow us to make ends meet); middle income (income is good enough for good nutrition and to buy the necessary things); and high income (our income now allows us to live comfortably). (6) Religion: Islam vs. Christianity and others; we dichotomized this variable because its distribution was highly skewed with Islam as the predominant religion followed by Christianity.

\subsection{Data Analysis}

Our analyses involved cross-sectional data and were conducted in two steps. First, prevalence of intention to quit by each independent variable among smokers was estimated. The $\chi^{2}$ test was utilized to assess whether intention to quit differed by these characteristics. Second, a single multivariate logistic regression equation was constructed to examine characteristics that remained significant with intention to quit; from which adjusted odds ratios and respective 95\% confidence intervals of each characteristic were derived. Multivariate logistic regression was used because it accounted for several confounding variables simultaneously. We applied sample weights, strata, and cluster variables to all analyses to account for the unequal probability of selection, oversampling, and nonresponse. A $p$-value $<0.05$ was considered statistically significant. SAS 9.4 software (SAS Institute, Cary, NC, USA) was used for all statistical analyses.

\section{RESULTS}

Overall, 75.9\% of smokers intended to quit smoking (Table 1).

\subsection{Prevalence of Intention to Quit}

Prevalence of intention to quit among smokers differed significantly across age groups $(p<0.001)$, level of education $(p<0.01)$, 
Table 1 Weighted PR, 95\% CI, and sample frequency of intention to quit, 2014 Global Adult Tobacco Survey - Kazakhstan

\begin{tabular}{|c|c|c|}
\hline \multirow{2}{*}{ Characteristics } & $\begin{array}{l}\text { Intended to quit } \\
\qquad(n=487)\end{array}$ & $\begin{array}{c}\text { Sample } \\
\text { frequency }\end{array}$ \\
\hline & PR $(95 \% \mathrm{CI})$ & $n(\%)$ \\
\hline Overall & $75.9(71.9-79.9)$ & $649(100.0)$ \\
\hline \multicolumn{3}{|l|}{ Age (years) ${ }^{* * *}$} \\
\hline $15-29$ & $84.5(78.3-90.7)$ & $119(20.9)$ \\
\hline $30-54$ & $80.3(76.1-84.5)$ & 417 (62.9) \\
\hline$\geq 55$ & $47.7(36.5-58.9)$ & $113(16.2)$ \\
\hline \multicolumn{3}{|l|}{ Gender } \\
\hline Male & $76.2(72.1-80.3)$ & $596(91.9)$ \\
\hline Female & $73.0(54.2-91.7)$ & $53(8.1)$ \\
\hline \multicolumn{3}{|l|}{ Education $^{* *}$} \\
\hline Low & $52.9(34.8-71.1)$ & $41(5.2)$ \\
\hline Secondary & $74.1(68.7-79.5)$ & $375(55.9)$ \\
\hline Higher & $81.6(76.7-86.5)$ & $233(38.9)$ \\
\hline \multicolumn{3}{|l|}{ Employment status ${ }^{\star * *}$} \\
\hline Unemployed & $59.9(50.1-69.7)$ & $155(23.0)$ \\
\hline Employed & $80.7(76.8-84.6)$ & $494(77.0)$ \\
\hline \multicolumn{3}{|l|}{ Income } \\
\hline Low & $69.7(61.7-77.6)$ & $169(25.1)$ \\
\hline Middle & $78.6(73.8-83.5)$ & $346(52.6)$ \\
\hline High & $76.5(67.8-85.1)$ & $134(22.3)$ \\
\hline \multicolumn{3}{|l|}{ Religion $^{* *}$} \\
\hline Islam & $80.5(75.9-85.2)$ & $382(62.4)$ \\
\hline Christianity and others & $68.2(61.0-75.4)$ & $267(37.7)$ \\
\hline \multicolumn{3}{|c|}{ Awareness of tobacco-related disease ${ }^{\star *}$} \\
\hline No & $70.1(64.3-75.9)$ & $343(51.8)$ \\
\hline Yes & $82.1(76.7-87.5)$ & $306(48.2)$ \\
\hline \multicolumn{3}{|l|}{ Nicotine dependence ${ }^{* * *}$} \\
\hline Low & $84.1(80.4-87.8)$ & $371(58.1)$ \\
\hline Moderate & $65.1(58.2-72.1)$ & $260(39.5)$ \\
\hline High & $55.0(25.6-84.3)$ & $18(2.4)$ \\
\hline \multicolumn{3}{|c|}{ Attempted to quit in the past 12 months ${ }^{\star * *}$} \\
\hline Yes & $91.9(87.6-96.3)$ & $183(29.1)$ \\
\hline No & $69.4(63.9-74.9)$ & $463(70.9)$ \\
\hline \multicolumn{3}{|c|}{ Household smoking restrictions ${ }^{* *}$} \\
\hline No & $60.6(49.9-71.2)$ & $121(18.3)$ \\
\hline Yes & $79.3(75.3-83.3)$ & $528(81.7)$ \\
\hline \multicolumn{3}{|c|}{ Awareness of antismoking messages } \\
\hline No & $72.5(67.1-78.0)$ & $333(50.2)$ \\
\hline Yes & $79.3(74.0-84.6)$ & $316(49.8)$ \\
\hline
\end{tabular}

$" p<0.01, " w p<0.001$. CI, confidence interval; PR, prevalence rate.

employment status $(p<0.001)$, and religion $(p<0.01)$. Intending to quit smoking was more prevalent among younger (15-29 years) smokers, and smokers who had a higher level of education, were identified with the religion of Islam, and were employed.

Prevalence of intention to quit also differed significantly by knowledge of tobacco-related diseases $(p<0.01)$, quit attempt in the past 12 months $(p<0.001)$, household smoking restrictions $(p<0.01)$, and nicotine dependence $(p<0.001)$. Intending to quit smoking was more prevalent among smokers who had low nicotine dependence, had knowledge of tobacco-related diseases, tried to stop smoking in the past 12 months, and had household restrictions on smoking.

\subsection{Regression Analyses}

Results from the univariate and multivariate logistic regression analyses are shown in Table 2.

\subsubsection{Univariate logistic regression}

In the univariate logistic regression models, secondary $(p<0.05)$ and higher $(p<0.01)$ education, middle income $(p<0.05)$, household restrictions $(p<0.01)$, awareness of tobacco-related diseases $(p<0.01)$, attempt to quit within the past 12 months $(p<0.001)$, and being employed $(p<0.001)$ were positively associated with intention to quit smoking. In contrast, older age $(p<0.001)$, identifying with Christianity and other religions $(p<0.01)$, and moderate $(p<0.001)$ and high $(p<0.05)$ nicotine dependence were negatively associated with intention to quit smoking.

\subsubsection{Multivariate logistic regression}

In the adjusted model, older age $(p<0.001)$ and moderate nicotine dependence $(p<0.001)$ remained negative correlates of intention to quit smoking. In contrast, awareness of tobacco-related diseases

Table 2 UOR, AOR, and 95\% CI of factors associated with intention to quit vs. not interested in quitting, 2014 Global Adult Tobacco Survey Kazakhstan

\begin{tabular}{|c|c|c|}
\hline Characteristics & UOR (95\% CI) & $\operatorname{AOR}(95 \% \mathrm{CI})$ \\
\hline \multicolumn{3}{|l|}{ Age (years) } \\
\hline 30-54 (vs. 15-29) & $0.75(0.43-1.30)$ & $0.74(0.42-1.29)$ \\
\hline$\geq 55$ (vs. 15-29) & $0.17(0.09-0.33)^{\star * *}$ & $0.20(0.10-0.41)^{\star * *}$ \\
\hline \multicolumn{3}{|l|}{ Gender } \\
\hline Male (vs. female) & $1.19(0.44-3.16)$ & $1.16(0.43-3.11)$ \\
\hline \multicolumn{3}{|l|}{ Education } \\
\hline Secondary (vs. low education) & $2.54(1.21-5.35)^{*}$ & $1.72(0.64-4.58)$ \\
\hline Higher (vs. low education) & $3.94(1.75-8.89)^{\star *}$ & $2.42(0.87-6.78)$ \\
\hline \multicolumn{3}{|l|}{ Employment status } \\
\hline Employed (vs. unemployed) & $2.80(1.76-4.44)^{* * *}$ & $1.17(0.67-2.06)$ \\
\hline \multicolumn{3}{|l|}{ Income } \\
\hline Middle (vs. low income) & $1.60(1.07-2.40)^{*}$ & $1.34(0.81-2.22)$ \\
\hline High (vs. low income) & $1.41(0.74-2.69)$ & $0.73(0.33-1.60)$ \\
\hline \multicolumn{3}{|l|}{ Religion } \\
\hline $\begin{array}{l}\text { Christianity and others } \\
\text { (vs. Islam) }\end{array}$ & $0.52(0.33-0.82)^{\star *}$ & $0.66(0.39-1.12)$ \\
\hline \multicolumn{3}{|c|}{ Awareness of tobacco-related disease } \\
\hline Aware (vs. not aware) & $1.96(1.25-3.07)^{\star *}$ & $1.83(1.19-2.80)^{\star *}$ \\
\hline \multicolumn{3}{|l|}{ Nicotine dependence } \\
\hline Moderate (vs. low) & $0.35(0.25-0.50)^{\star * *}$ & $0.36(0.24-0.54)^{\star * *}$ \\
\hline High (vs. low) & $0.23(0.07-0.76)^{\star}$ & $0.30(0.08-1.19)$ \\
\hline \multicolumn{3}{|c|}{ Attempted to quit in the past 12 months } \\
\hline Yes vs. No & $5.01(2.59-9.69)^{\star * *}$ & $4.62(2.29-9.32)^{\star * *}$ \\
\hline \multicolumn{3}{|l|}{ Household smoking restrictions } \\
\hline $\begin{array}{l}\text { Having restrictions } \\
\text { (vs. having no restrictions) }\end{array}$ & $2.50(1.50-4.18)^{\star *}$ & $2.56(1.47-4.47)^{* * *}$ \\
\hline \multicolumn{3}{|c|}{ Awareness of antismoking messages } \\
\hline Aware (vs. not aware) & $1.45(0.97-2.17)$ & $0.97(0.59-1.59)$ \\
\hline
\end{tabular}

" $p<0.05, " * p<0.01,{ }^{* * *} p<0.001$. AOR, adjusted odds ratio; CI, confidence interval; UOR, unadjusted odds ratio. 
( $p<0.01)$, household restrictions on smoking $(p<0.001)$, and attempting to quit within the past 12 months $(p<0.001)$ remained positive correlates of intention to quit smoking.

Compared with younger smokers, older smokers ( $\geq 55$ years) had five times lower odds of intention to quit smoking. However, no significant difference was observed between middle-aged and younger smokers. The odds of intention to quit smoking were 2.8 times lower among smokers with moderate vs. low nicotine dependence. Smokers who tried to stop smoking in the past 12 months, those who had household restrictions on smoking, and those aware of tobacco-related diseases had 4.62, 2.56, and 1.83 times higher odds of intention to quit smoking, respectively.

\section{DISCUSSION}

To our knowledge, this is the first study examining the prevalence and correlates of intention to quit smoking among a nationally representative sample of smokers in Kazakhstan. Overall, we found $75.9 \%$ of the respondents intended to quit smoking, and this rate is comparable with rates (64.7-81.5\%) from four high-income countries [18]. We also found the odds of intention to quit significantly lower among smokers aged $\geq 55$ years, and those with moderate nicotine dependence. We found that the odds of intention to quit significantly higher among smokers who attempted to stop smoking in the past 12 months, had household restrictions on smoking, and had knowledge of tobacco-related diseases.

Our finding for older smokers having lower odds of quitting intention than younger ones is consistent with existing research in other countries [29-32]. One such study exploring beliefs about quitting among older smokers from the United Kingdom, United States, Canada, and Australia found that older smokers were less willing to quit because they perceived themselves as less vulnerable to the harms of smoking, less concerned about health effects of smoking, or confident about being able to quit successfully [31]. In a qualitative study exploring older smokers' views on stopping smoking, Kerr et al. [33] reported that older smokers believed any damage from smoking would have already occurred so there was no point in quitting. In light of these findings, it is possible that the older smokers in the GATS-Kazakhstan sample might share similar attitudes and beliefs about stopping smoking, leading to lower odds of quitting intention overall; however, we were unable to determine the exact causes. We suggest that further research is needed to examine obstacles to cessation among older smokers in Kazakhstan. Understanding these obstacles may facilitate cessation activities; the benefit of which includes reduced mortality and additional healthy life years for those aged $\geq 65$ years [34,35].

Research from developed countries indicates that most smokers were aware of the major health risks of smoking, such as lung cancer and stroke $[36,37]$. One such study surveyed smokers in the United States, Canada, Australia, and the United Kingdom, finding that $94 \%$ and $89 \%$ of respondents believed smoking caused lung cancer and heart diseases, respectively [38]. Yet, the same level of knowledge has not been found in low- and middle-income countries. For example, a study using the 2010 International Tobacco Control data reported $85 \%$ of smokers in Bangladesh believed smoking caused lung cancer and 79\% believed smoking caused heart disease [39]. Similarly, another study using the 2009 International Tobacco Control data found $86 \%$ of smokers in
Bhutan believed that smoking caused lung cancer [40]. In the 2014 GATS-Kazakhstan sample, this knowledge was assessed as being aware of six or more of the 12 common tobacco-related diseases. However, we only found $48 \%$ of smokers in Kazakhstan had such level of knowledge, and moreover, the odds of intending to quit were higher among them. These findings highlight the need for public health education on all aspects of tobacco-related diseases in Kazakhstan. We suggest prevention efforts should be directed toward providing smokers as well as the general public with comprehensive information on the negative health consequences of cigarette smoking. Widespread dissemination of research showing the harms of tobacco use on health has been particularly effective among populations in which knowledge of tobacco-related health concerns is low, as is often seen in emerging economies [41].

Most existing research has found that intention to quit smoking decreases with nicotine dependence $[18,19,42]$. However, a number of studies have also found that nicotine dependence is not associated with quitting intention among smokers $[43,44]$. In the current study, we discovered a significant negative association between nicotine dependence and intention to quit smoking, that was, the higher the dependence, the lower the intention to quit smoking. However, this significance only applied to moderate vs. low dependence in the adjusted model. This finding may be attributed to the distribution of nicotine dependence in our sample, as the majority of smokers had low $(58 \%)$ or moderate $(40 \%)$ dependence, while only $2 \%$ had high dependence. Smokers with high nicotine dependence are usually treated with costly interventions, such as nicotine replacement therapy, to help them reduce consumption of tobacco [45]. Given that most smokers in our sample had moderate nicotine dependence, which was associated with lower odds of quitting intention, we suggest investing in cessation strategies targeting smokers with moderate nicotine dependence instead of in costly nicotine replacement therapies meant for smokers with high nicotine dependence.

Consistent with findings from previous studies [45], we found that those who attempted to stop smoking had 4.6 times higher odds of quitting intention than those who did not make a quit attempt. This finding indicates that, even if the initial quit attempts were not successful, a smoker's intention to quit will likely remain high, and subsequent quit attempts could propel the smoker toward eventual successful quitting. In addition, our finding of the majority of smokers $(82 \%)$ having household restrictions on smoking and a positive relation with intention to quit smoking indicates a social climate against smoking. Previous studies have shown that national smoke-free legislation may prompt smokers to establish total smoking bans in their homes [46]. Perhaps the current effort in Kazakhstan to ban smoking in public places has an impact on smoking bans at homes too [27].

The current study had several limitations. First, GATS was a cross-sectional survey, thus, we were not able to defer causal relationships of the intention to quit smoking and its correlates. Longitudinal studies are needed to confirm the temporal sequence of these relationships. Second, GATS was a self-reported measure, and like all self-reported measures, it may have been influenced by social desirability biases.

Despite these limitations, this study fills a gap in the literature by examining the prevalence and correlates of intention to quit among smokers in Kazakhstan for the first time. The current tobacco control policies in Kazakhstan mainly focus on banning smoking in public places; restricting tobacco advertising, promotion, and 
sponsorship; regulating placement of health warnings on tobacco products; and raising tobacco-related taxes [27]. Our findings suggest that, to implement Article 12 of the WHO Framework Convention on Tobacco Control in Kazakhstan [47], more efforts need to be invested in the provision of cessation services for all smokers regardless of age, in delivering comprehensive health education about the risks of tobacco use for the general public, and in upholding and strengthening existing policies on smoking bans. Moreover, cessation services should emphasize that quitting at any age is beneficial [48], and focus on provision of services to smokers with light and moderate nicotine dependence.

\section{CONFLICTS OF INTEREST}

None.

\section{REFERENCES}

[1] World Health Organization (WHO). WHO global report on trends in prevalence of tobacco smoking 2000-2025, second edition. Geneva: WHO; 2018. Available from: http://www.wpro. who.int/mediacentre/releases/2018/who_tobacco_trends.pdf.

[2] Zhylkaidarova A, Nurguzhayev K. Expansion of the Quit \& Win competition in Kazakhstan as the instrument of the building capacity for a tobacco-free society. Poster session presented at The 13th World Conference on Tobacco OR Health, Washington DC, U.S., July 13th, 2006. Available from: https://2006.confex. com/uicc/wctoh/techprogram/P3865.HTM.

[3] World Health Organization (WHO). Kazakhstan. 2014 report. In: FCTC implementation database, 2014. Geneva: WHO. Available from: http://apps.who.int/fctc/implementation/database/parties/ kazakhstan (in Russian).

[4] The Tobacco Atlas. Consumption. American Cancer Society; Vital Strategies; 2019. Available from: https://tobaccoatlas.org/ topic/consumption.

[5] Lopez AD. Alcohol and smoking as risk factors. In: Chamie J, Cliquet RL, editors. Health and mortality: issues of global concern (Proceedings of the United Nations Symposium on Health and Mortality, Brussels, 19-22 November, 1997.). New York: United Nations Population Division; 1999.

[6] U.S. Department of Health and Human Services. The Health Consequences of Smoking: 50 Years of Progress. A Report of the Surgeon General. Atlanta, GA: U.S. Department of Health and Human Services, Centers for Disease Control and Prevention, National Center for Chronic Disease Prevention and Health Promotion, Office on Smoking and Health, 2014.

[7] U.S. Department of Health and Human Services. Smoking and cancer (fact sheet). Atlanta, GA: US Department of Health and Human Services, Centers for Disease Control and Prevention, National Center for Chronic Disease Prevention and Health Promotion, Office on Smoking and Health, 2014.

[8] U.S. Department of Health and Human Services. Smoking and diabetes (fact sheet). Atlanta, GA: US Department of Health and Human Services, Centers for Disease Control and Prevention, National Center for Chronic Disease Prevention and Health Promotion, Office on Smoking and Health, 2014.

[9] U.S. Department of Health and Human Services. Smoking and respiratory diseases (fact sheet). Atlanta: US Department of
Health and Human Services, Centers for Disease Control and Prevention, National Center for Chronic Disease Prevention and Health Promotion, Office on Smoking and Health; 2014.

[10] World Health Organization (WHO). Guidelines for implementation of the WHO Framework Convention on Tobacco Control. Geneva: WHO; 2011.

[11] Decree of the President of the Republic of Kazakhstan № 193-IV ZRK from 18.09.2009, the "The Code on health of people and health care system".

[12] World Health Organization (WHO). Global Adult Tobacco Survey. Fact sheet. Kazakhstan 2014. Geneva: WHO. Available from: http://www.who.int/tobacco/surveillance/survey/gats/ kazfactsheet.pdf.

[13] Nguyen AB, Zhao X, Hoffman L, Morse AL, Delahanty J. Nicotine and addiction beliefs and perceptions among the US-born and foreign-born populations. Prev Med 2018;114;107-14.

[14] Jha P, Peto R. Global effects of smoking, of quitting, and of taxing tobacco. N Engl J Med 2014;370;60-8.

[15] Horn K, Ali M, Gray T, Anesetti-Rothermel A, Branstetter S. School-level disadvantage and failed cessation treatment among adolescent smokers. Tob Prev Cessation 2018;4;11.

[16] Jiang N, Ho SY, Wang MP, Leung LT, Lam TH. Exclusive and concurrent use of cigarettes and alternative tobacco products among Hong Kong adolescents. Tob Prev Cessation 2018;4;19.

[17] Ajzen I. The theory of planned behavior. Organ Behav Hum Decis Process 1991;50;179-211.

[18] Hyland A, Borland R, Li Q, McNeill A, Fong GT, O'Connor RJ, et al. Individual-level predictors of cessation behaviours among participants in the International Tobacco Control (ITC) Four Country Survey. Tob Control 2006;15;iii83-iii94.

[19] Hyland A, Li Q, Bauer JE, Giovino GA, Steger C, Cummings KM. Predictors of cessation in a cohort of current and former smokers followed over 13 years. Nicotine Tob Res 2004;6;S363-S9.

[20] Feng G, Jiang Y, Li Q, Yong HH, Elton-Marshall T, Yang J, et al. Individual-level factors associated with intentions to quit smoking among adult smokers in six cities of China: findings from the ITC China Survey. Tob Control 2010;19;i6-i11.

[21] Yang J, Hammond D, Driezen P, Fong GT, Jiang Y. Health knowledge and perception of risks among Chinese smokers and non-smokers: findings from the Wave 1 ITC China Survey. Tob Control 2010;19;i18-i23.

[22] Gilpin EA, White MM, Farkas AJ, Pierce JP. Home smoking restrictions: which smokers have them and how they are associated with smoking behavior. Nicotine Tob Res 1999;1;153-62.

[23] de Betânia Caixeta R, Sinha DN, Khoury RN, Rarick J, Fouad H, Tursan d'Espaignet E, et al. Antismoking messages and intention to quit - 17 countries, 2008-2011. MMWR Morb Mortal Wkly Rep 2013;62;417-22.

[24] Stockings SE, Bowman J, McElwaine K, Baker A, Terry M, Clancy $\mathrm{R}$, et al. Readiness to quit smoking and quit attempts among Australian mental health inpatients. Nicotine Tob Res 2013;15;942-9.

[25] Global Adult Tobacco Survey Collaborative Group. Global Adult Tobacco Survey (GATS): sample design manual, version 2.0. Atlanta: Centers for Disease Control and Prevention, 2010.

[26] Global Adult Tobacco Survey the Republic of Kazakhstan 2014 Country Report. Ministry of Healthcare and Social Development of the Republic of Kazakhstan; 2014. Available from: http://www. who.int/tobacco/surveillance/survey/gats/gats_kazakhstan_ country_report_2014.pdf 
[27] Heatherton TF, Kozlowski LT, Frecker RC, Fagerstrom KO. The Fagerström test for nicotine dependence: a revision of the Fagerstrom tolerance questionnaire. Br J Addict 1991;86; 1119-27.

[28] Kozlowski LT, Porter CQ, Orleans CT, Pope MA, Heatherton T. Predicting smoking cessation with self-reported measures of nicotine dependence: FTQ, FTND, and HSI. Drug Alcohol Depend 1994;34;211-6.

[29] Popova L, Majeed B, Owusu D, Spears CA, Ashley DL. Who are the smokers who never plan to quit and what do they think about the risks of using tobacco products? Addict Behav $2018 ; 87 ; 62-8$.

[30] Nagelhout GE, Crone MR, van den Putte B, Willemsen MC, Fong GT, de Vries H. Age and educational inequalities in smoking cessation due to three population-level tobacco control interventions: findings from the International Tobacco Control (ITC) Netherlands Survey. Health Educ Res 2013;28;83-91.

[31] Yong HH, Borland R, Siahpush M. Quitting-related beliefs, intentions, and motivations of older smokers in four countries: findings from the international tobacco control policy evaluation survey. Addict Behav 2005;30;777-88.

[32] Owusu D, Quinn M, Wang KS, Aibangbee J, Mamudu HM. Intentions to quit tobacco smoking in 14 low- and middleincome countries based on the transtheoretical model. Drug Alcohol Depend 2017;178;425-9.

[33] Kerr S, Watson H, Tolson D, Lough M, Brown M. Smoking after the age of 65 years: a qualitative exploration of older current and former smokers' views on smoking, stopping smoking, and smoking cessation resources and services. Health Soc Care Community 2006;14;572-82.

[34] Østbye T, Taylor DH. The effect of smoking on years of healthy life (YHL) lost among middle-aged and older Americans. Health Serv Res 2004;39;531-52.

[35] Taylor DH, Hasselblad V, Henley SJ, Thun MJ, Sloan FA. Benefits of smoking cessation for longevity. Am J Public Health 2002;92;990-6.

[36] Siahpush M, McNeill A, Hammond D, Fong GT. Socioeconomic and country variations in knowledge of health risks of tobacco smoking and toxic constituents of smoke: results from the 2002 International Tobacco Control (ITC) Four Country Survey. Tob Control 2006;15;iii65-iii70.
[37] Weinstein N, Slovic P, Waters E, Gibson G. Public understanding of the illnesses caused by cigarette smoking. Nicotine Tob Res $2004 ; 6 ; 349-55$.

[38] Hammond D, Fong GT, Borland R, McNeill A, Cummings KM, Hastings G. Effectiveness of cigarette warning labels in informing smokers about the risks of smoking: findings from the International Tobacco Control (ITC) Four Country Survey. Tob Control 2006;15;iii19-iii25.

[39] The International Tobacco Control Policy Evaluation Project. ITC Bangladesh report on tobacco warning labels. Waterloo, Ontario: University of Waterloo; Dhaka: University of Dhaka; 2011.

[40] The International Tobacco Control Policy Evaluation Project. ITC Bhutan project report. Waterloo, Ontario: University of Waterloo; Thimpu, Bhutan: Ministry of Health; 2011.

[41] Jha P, Chaloupka FJ. Curbing the epidemic: governments and the economics of tobacco control. Washington: World Bank; 1999.

[42] Marques-Vidal P, Melich-Cerveira J, Paccaud F, Waeber G, Vollenweider P, Cornuz J. Prevalence and factors associated with difficulty and intention to quit smoking in Switzerland. BMC Public Health 2011;11;227.

[43] Reitzel LR, Costello TJ, Mazas CA, Vidrine JI, Businelle MS, Kendzor DE, et al. Low-level smoking among Spanish-speaking Latino smokers: relationships with demographics, tobacco dependence, withdrawal, and cessation. Nicotine Tob Res 2009;11;178-84.

[44] Kaai SC, Chung-Hall J, Sun MC, Burhoo P, Moussa L, Yan M, et al. Predictors of quit intentions among adult smokers in Mauritius: Findings from the ITC Mauritius Survey. Tob Prev Cessation 2016;2;75.

[45] Hyland A, Levy DT, Rezaishiraz H, Hughes JR, Bauer JE, Giovino GA, et al. Reduction in amount smoked predicts future cessation. Psychol Addict Behav 2005;19;221-5.

[46] Mons U, Nagelhout GE, Allwright S, Guignard R, van den Putte $\mathrm{B}$, Willemsen MC, et al. Impact of national smoke-free legislation on home smoking bans: findings from the International Tobacco Control Policy Evaluation Project Europe Surveys. Tob Control 2013;22;e2-e9.

[47] World Health Organization (WHO). WHO framework convention on tobacco control. Geneva: WHO, 2003.

[48] Thun MJ, Carter BD, Feskanich D, Freedman ND, Prentice R, Lopez $\mathrm{AD}$, et al. 50-year trends in smoking-related mortality in the United States. N Engl J Med 2013;368;351-64. 